\title{
Nutrition and respiratory health in adults: findings from the Health Survey for Scotland
}

\author{
Y. Kelly, A. Sacker, M. Marmot
}

Nutrition and respiratory health in adults: findings from the Health Survey for Scotland. Y. Kelly, A. Sacker, M. Marmot. C) ERS Journals Ltd 2003.

ABSTRACT: There is a growing body of evidence to support the hypothesised links between consumption of antioxidant rich foods and the occurrence of obstructive airway disease. The main research question was to examine the relationships between two types of dietary exposure and two indicators of respiratory morbidity in Scottish adults.

The relationships between dietary consumption of fruit, vegetables and fish, and plasma levels of vitamins $\mathrm{A}, \mathrm{C}, \mathrm{E}$ and $\boldsymbol{\beta}$-carotene, and pulmonary function (forced expiratory volume in one second (FEV1)) and symptoms (phlegm production and shortness of breath with wheezing), were examined in a random population sample of adults.

A dose/response relationship was found between fruit consumption and pulmonary function. In comparison with eating fruit rarely or never, eating fruit at least once per day, 1-6 times per week, and 1-3 times per month were associated with differences of 132, 100 and $63 \mathrm{~mL}$ in FEV1, after adjustment for known confounders and dietary intake of vegetables and fish $(n=6186)$. An SD score change in plasma vitamin $C$ was associated with a $49 \mathrm{~mL}$ difference in FEV1 $(\mathrm{n}=930)$. Fruit and vitamin $E$ were associated with a reduced prevalence of phlegm production for 3 months or more per year.

The most beneficial combination of dietary components may be found in natural foodstuffs, particularly fresh fruit.

Eur Respir J 2003; 21: 664-671.
International Centre for Health and Society, Dept of Epidemiology and Public Health, Royal Free and University College Medical School, London, UK.

Correspondence: Y. Kelly, International Centre for Health and Society, Dept of Epidemiology and Public Health, Royal Free and University College Medical School, 1-19 Torrington Place, London WCIE 6BT, UK.

Fax: 442078130280

E-mail: y.kelly@public-health.ucl.ac.uk

Keywords: Antioxidants, diet, pulmonary function, respiratory symptoms

Received: June 282002

Accepted after revision: December 22002

The 1995 Health Survey for Scotland was funded by the Scottish Office. Y. Kelly is funded by the Higher Education Funding Council for England, A. Sacker and M. Marmot are funded by the Medical Research Council.
Improved understanding of factors that could potentially be modified in order to reduce morbidity from respiratory disease is clearly desirable.

The hypothesised association between antioxidant and omega-3 fatty acids and/or the foods rich in these, and aspects of airways disease, has biological plausibility. Particular antioxidants, such as vitamins $\mathrm{A}, \mathrm{C}$ and $\mathrm{E}$, and $\beta$-carotene, protect body tissues from potentially harmful oxidative damage, [1] and omega-3 fatty acids, which are present in fish, have been shown to reduce the potency of inflammatory mediators, such as prostaglandin $\mathrm{E}_{2}[2]$.

Consumption of fresh fruit has been positively associated with pulmonary function, both cross-sectionally [3-6] and longitudinally [7]. Fruit intake has also been linked to reduced prevalence of respiratory symptoms, particularly those of airway obstruction, such as wheeze [8, 9]. Reported associations between fish intake and pulmonary function $[4,5,10]$ and reduced prevalence of symptoms [11] are equivocal.

Few studies have examined the relationship between plasma nutrient levels and respiratory health. Of those that have, positive associations have been reported between pulmonary function and plasma vitamin $\mathrm{C}[12,13], \mathrm{A}[14,15], \mathrm{E}$ [13], and $\beta$-carotene [13, 15]. Furthermore, lower rates of bronchitis and wheeze have been linked to higher plasma levels of vitamin $\mathrm{C}$ [11]. These reports have been limited because they have only considered one or two of these blood analytes on any one occasion.

Variations in the types of explanatory factors studied and their measurement, whether it is dietary intake of fruits, vegetables and fish, specific micronutrients, or plasma vitamin levels, and variations in the measurement of disease outcome, have led to inconsistencies in reported associations between diet and respiratory health. In order to clarify these relationships, the authors examined the effects of two sets of exposures, namely dietary intakes (of fruit, vegetables and fish) and plasma analytes (vitamins $\mathrm{C}, \mathrm{A}$ and $\mathrm{E}$ and $\beta$-carotene) on two indicators of airway disease, namely symptoms (phlegm production and shortness of breath with wheeze) and pulmonary function (forced expiratory volume in one second (FEV1)) in the same subjects. The major dietary sources of antioxidant vitamins in this population include fruits and vegetables [16].

Data was analysed from a large random population sample of Scottish adults from the 1995 Health Survey for Scotland.

\section{Subjects and methods}

Sample

The1995 Scottish Health Survey was conducted to obtain data on the health of the working age population (16-64 yrs) living in private households. The sample is described in detail in the Scottish Health Survey [17]. Briefly, a random sample of addresses was selected from 312 postcode sectors across Scotland. A letter was sent to each address informing residents that their household had been selected for inclusion in the survey. Each address was then visited by an interviewer 
who randomly selected one eligible resident. In total, 7,932 people were interviewed. The second stage of the survey was a nurse visit during which height, weight and pulmonary function measurements were taken $(n=6,958,88 \%$ of the sample), and with written consent a blood sample was obtained ( $n=6,183,78 \%$ of the sample). For practical reasons it was only possible to measure plasma vitamin and carotenoid levels in a subsample of participants, as blood samples had to be processed and frozen within $4 \mathrm{~h}$ of venepuncture. Therefore, only postcode sectors $\leqslant 1 \mathrm{~h}$ drive of one of the seven processing laboratories were eligible for these analyses $(n=1,146)$. Participants included in the plasma vitamin and carotenoid analyses were thus more heavily concentrated in urban areas. The subsample was similar to the whole study sample in age, sex, height, weight, smoking status and social class (table 1). These participants were more likely to report respiratory symptoms (table 2), although mean FEV1 levels were the same in the subsample as the whole study sample.

\section{Data collection}

Interviews were carried out using Computer Assisted Personal Interviewing, whereby informants' responses are entered directly onto a laptop computer.

Explanatory variables. Participants were asked how often they ate fresh fruit, raw vegetables, cooked green and root vegetables, white and nonwhite fish (see Appendix 1).

Immediately after venepuncture, blood samples were refrigerated and stored in the dark. On arrival at the laboratory, samples were processed and frozen at $-40^{\circ} \mathrm{C}$. Of the 1,146 blood samples obtained, 40 were not analysed for vitamins A, $\mathrm{E}$ and $\beta$-carotene due to technical difficulties, 1,026 samples were analysed for vitamin $\mathrm{C}$ levels and 80 samples were not analysed either because of technical reasons or because participants had consumed fruit or fruit juice $<1 \mathrm{~h}$ before venepuncture. Vitamins $\mathrm{A}, \mathrm{C}, \mathrm{E}$ and $\beta$-carotene were measured using high-pressure liquid chromatography techniques $[19,20]$. As recommended, vitamin E levels were adjusted for the amount of cholesterol in the blood.

Confounders. Data were collected on known confounding factors. Those included in regression models were as follows: 1) social class of head of household (I+II (professional and managerial), III (skilled nonmanual), III (skilled manual), IV+V (semi- and unskilled manual)) [18]; 2) cigarette smoking status (never, ex, current); 3) average number of cigarettes smoked per day (none, 1-10, 11-20, >20); 4) activity levels: work and leisure (inactive, light, moderate, vigorous).

Outcomes. The occurrence of the symptoms of phlegm production and attacks of shortness of breath with wheezing were assessed (see Appendix 2).

Pulmonary function was assessed by spirometry using a Vitalograph Escort Spirometer (Vitalograph, Buckingham, UK). The best of five FEV1 measurements were used in analysis for participants who had performed the manoeuvre satisfactorily.

\section{Data analysis}

Symptoms. The effects of dietary consumption and plasma analytes on respiratory symptoms were estimated using logistic regression analysis.

To estimate the effect of fruit, vegetable and fish intake,
Table 1.-Social, demographical, physical and dietary characteristics of study population

\begin{tabular}{|c|c|c|}
\hline & Whole sample & Subsample \\
\hline \multicolumn{3}{|l|}{ Social class } \\
\hline $\mathrm{I}+\mathrm{II}^{\#}$ & $2430(30.6)$ & $336(31.4)$ \\
\hline IIINM ${ }^{\top}$ & $1217(15.3)$ & $175(16.3)$ \\
\hline IIIM $^{+}$ & $2161(27.2)$ & $278(26.0)$ \\
\hline $\mathrm{IV}+\mathrm{V}^{\S}$ & $1638(20.7)$ & $226(21.1)$ \\
\hline Other & $476(6.0)$ & $56(5.2)$ \\
\hline Total & 7922 & 1071 \\
\hline \multicolumn{3}{|l|}{ Smoking status } \\
\hline Never & 3518 (44.4) & $484(45.2)$ \\
\hline Exregular & $1490(18.8)$ & $200(18.7)$ \\
\hline Current & $2921(36.8)$ & $387(36.1)$ \\
\hline Total & 7929 & 1071 \\
\hline \multicolumn{3}{|l|}{ Cigarettes $\cdot$ day $^{-1}$} \\
\hline None & $5008(63.2)$ & $684(63.9)$ \\
\hline$<10$ & $517(6.5)$ & $61(5.7)$ \\
\hline $10-20$ & $1152(14.5)$ & $151(14.1)$ \\
\hline$>20$ & 1246 (15.7) & $175(16.3)$ \\
\hline Total & 7923 & 1071 \\
\hline \multicolumn{3}{|l|}{ Sex } \\
\hline Male & $3524(44.4)$ & $518(48.4)$ \\
\hline Female & $4408(55.6)$ & $553(51.6)$ \\
\hline Total & 7932 & 1071 \\
\hline \multicolumn{3}{|l|}{ Dietary intake } \\
\hline \multicolumn{3}{|l|}{ Fruit } \\
\hline 1-6 day & $1472(18.6)$ & 204 (18.7) \\
\hline $1-6$ week & $4285(54.0)$ & $576(52.8)$ \\
\hline $1-3$ month & $1444(18.2)$ & $193(17.7)$ \\
\hline Rarely/never & $730(9.2)$ & $117(10.8)$ \\
\hline Total & 7931 & 1091 \\
\hline \multicolumn{3}{|l|}{ Green vegetables } \\
\hline$\geqslant 1$ day & $2283(28.8)$ & $297(26.4)$ \\
\hline $1-6$ week & 4853 (61.2) & $681(62.2)$ \\
\hline Rarely/never & $795(10.0)$ & $123(11.4)$ \\
\hline Total & 7931 & 1091 \\
\hline \multicolumn{3}{|l|}{ Raw vegetables } \\
\hline$\geqslant 1$ day & $682(8.6)$ & $84(7.6)$ \\
\hline $1-6$ week & 4933 (62.2) & $679(62.1)$ \\
\hline Rarely/never & $2315(29.2)$ & $338(30.3)$ \\
\hline Total & 7931 & 1091 \\
\hline \multicolumn{3}{|l|}{ Root vegetables } \\
\hline$\geqslant 1$ day & $1243(15.7)$ & 147 (12.7) \\
\hline $1-6$ week & $5460(68.8)$ & $786(71.8)$ \\
\hline Rarely/never & $1228(15.5)$ & $168(15.5)$ \\
\hline Total & 7931 & 1091 \\
\hline \multicolumn{3}{|l|}{ Nonwhite fish } \\
\hline$\geqslant 1$ week & $2897(36.5)$ & $399(36.3)$ \\
\hline 1-3 month & $2150(27.1)$ & $292(26.6)$ \\
\hline Rarely/never & $2884(36.4)$ & $410(37.1)$ \\
\hline Total & 7931 & 1091 \\
\hline \multicolumn{3}{|l|}{ White fish } \\
\hline$\geqslant 1$ week & $4337(54.7)$ & $619(56.2)$ \\
\hline $1-3$ month & $1955(24.6)$ & $267(24.4)$ \\
\hline Less often/never & 1639 (20.7) & $215(19.4)$ \\
\hline Total & 7931 & 1091 \\
\hline \multicolumn{3}{|l|}{ Subjects $n$} \\
\hline Male & 3524 & 533 \\
\hline Female & 4408 & 568 \\
\hline \multicolumn{3}{|l|}{ Age yrs } \\
\hline Male & $40.4 \pm 13.3$ & $40.7 \pm 13.2$ \\
\hline Female & $40.3 \pm 13.3$ & $40.2 \pm 12.8$ \\
\hline \multicolumn{3}{|l|}{ Height $\mathrm{cm}$} \\
\hline Male & $174.7 \pm 7.0$ & $174.5 \pm 7.0$ \\
\hline Female & $161.3 \pm 6.3$ & $160.8 \pm 5.8$ \\
\hline Weight kg & & \\
\hline Male & $79.98 \pm 13.4$ & $80.3 \pm 13.1$ \\
\hline Female & $67.08 \pm 13.2$ & $65.5 \pm 12.8$ \\
\hline
\end{tabular}

Data are presented as $\mathrm{n}(\%)$ or mean \pm SD unless otherwise stated. \#: professional and managerial; ": skilled nonmanual; ${ }^{+}$: skilled manual; ${ }^{\S}$ : semi- and unskilled manual [18]. 
Table 2. - Prevalence of respiratory symptoms and mean pulmonary function measurements

\begin{tabular}{lrr}
\hline & Whole sample & Subsample \\
\hline Symptom & & \\
Phlegm in the morning in winter & $7932(17.2)$ & $1071(19.2)$ \\
Phlegm $\geqslant 3$ months & $7928(11.0)$ & $1071(13.2)$ \\
SOB with attacks of wheeze & $7928(14.4)$ & $1071(17.6)$ \\
Pulmonary function FEV1 & & $526(2.69 \pm 0.72)$ \\
Male & $3050(3.76 \pm 0.99)$ & $557(2.68 \pm 0.68)$ \\
Female & $3659(3.76 \pm 0.99)$ & \\
\hline
\end{tabular}

Data are presented as $\mathrm{n}(\%)$ and mean \pm SD. SOB: Shortness of breath; FEV1: forced expiratory volume in one second.

frequency of consumption categories were entered into the models as categorical variables. To assess whether there was a dose response relationship, fruit, vegetable and fish consumption categories were entered into models as continuous variables. $\mathrm{SD}$ scores ( $\mathrm{Z}$ scores) for plasma analytes were generated, and were used as continuous variables.

A three-stage modelling process was used to adjust for known confounders. Model A adjusted for age and sex, model $\mathrm{B}$ added in social class, cigarette smoking, and activity levels, and in model $\mathrm{C}$ additional adjustment was made for either other dietary intakes or other plasma analyte levels.

Pulmonary function. Using multiple linear regression, maximum FEV1 was regressed against dietary intake of fruit, vegetables and fish, and adjusted in three stages for the confounders age, age ${ }^{2}$, height, height ${ }^{2}$ and sex in model $\mathrm{A}$; social class, smoking status, number of cigarettes smoked per day and overall activity level in model B; and other dietary intakes or other plasma analytes in model $\mathrm{C}$.

Differences in lung function (calculated for an individual of average height $1.67 \mathrm{~m}$ ) for dietary intakes are presented using the lowest intake as the reference category. A test for dose/ response was performed by entering fruit, vegetable and fish intake categories as continuous variables.

Models A, B and C were run with plasma vitamins and carotenoids as the explanatory variables. There was no deviation from linearity in the relationship between lung function and plasma analyte levels and so these predictors were entered as continuous SD scores. Differences in lung function for a one SD increase in plasma vitamin and carotenoid levels are presented.

Fruit intake and plasma vitamins were included in the same model to test whether the effect of fresh fruit on pulmonary function is due to its vitamin content. Models were also run to estimate the simultaneous affects of fruit intake and plasma vitamins on the occurrence of phlegm symptoms. Three models are presented, model A has fruit consumption as the explanatory variable, adjusting for confounders, model B has plasma analytes as the explanatory variables adjusting for the same confounders, and model $\mathrm{C}$ simultaneously estimates the effects of fruit intake and plasma analytes after adjustments.

To examine the possible residual confounding in associations between explanatory and outcome variables, all models were run separately for smokers and nonsmokers, nonmanual and manual social classes and levels of activity (inactive, light, moderate and vigorous). Also tested were two-way interactions between both dietary and plasma variables and social class, smoking and activity levels, in turn. There were no differences in the effect estimates when stratifications were used, and neither were there any significant interactions between the explanatory variables and the confounders. Therefore, results for all participants are presented.

\section{Results}

Mean \pm sD plasma levels of vitamin $\mathrm{C}, \mathrm{A}$, and $\beta$-carotene were $34.6 \pm 23.6,2.47 \pm 0.79$, and $0.36 \pm 0.26 \mu \mathrm{mol} \cdot \mathrm{L}^{-1}$, respectively, and mean vitamin E:cholesterol was $5.43 \pm 1.46$. Vitamin $C$ levels correlated with those of vitamin $A$ and $\beta$-carotene $(0.26$ and 0.25 , respectively) but not with vitamin $\mathrm{E}$, and vitamins $\mathrm{A}$

Table 3.-Difference in forced expiratory volume in one second $(\mathrm{mL})$ by frequency of fresh fruit, vegetables and fish intake, compared to lowest intake category

\begin{tabular}{|c|c|c|c|}
\hline & Model A & Model B & Model C \\
\hline \multicolumn{4}{|l|}{ Fresh fruit ${ }^{\#}$} \\
\hline$\geqslant 1$ day & $280(229-332)$ & $159(105-213)$ & $132(77-188)$ \\
\hline 1-6 week & $205(159-250)$ & $119(72-157)$ & $100(52-147)$ \\
\hline 1-3 month & $111(60-162)$ & $72(20-123)$ & $63(11-115)$ \\
\hline F statistic (df) & $47.3(36584)$ & $12.9(36185)$ & $8.1(36184)$ \\
\hline p-value & $* * *$ & *** & $* * *$ \\
\hline \multicolumn{4}{|l|}{ Green vegetables } \\
\hline$\geqslant 1$ day & $164(116-211)$ & $106(57-155)$ & $91(32-150)$ \\
\hline $1-6$ week & $118(73-62)$ & $72(27-117)$ & $57(9-105)$ \\
\hline F statistic (df) & $22.4(26584)$ & $9.2(26185)$ & $4.6(26184)$ \\
\hline p-value & $* * *$ & $* * *$ & 0.003 \\
\hline \multicolumn{4}{|l|}{ Raw vegetables } \\
\hline$\geqslant 1$ day & $143(93-192)$ & $82(32-133)$ & $39(-14-92)$ \\
\hline $1-6$ week & $96(68-125)$ & $49(20-78)$ & $25(-6-55)$ \\
\hline F statistic (df) & $26.9(26584)$ & $7.3(26185)$ & $1.6(26185)$ \\
\hline $\mathrm{p}$-value & $* * *$ & $* * *$ & 0.077 \\
\hline \multicolumn{4}{|l|}{ Root vegetables } \\
\hline$\geqslant 1$ day & $84(37-130)$ & $41(-6-88)$ & $-44(-101-14)$ \\
\hline 1-6 week & $78(41-114)$ & $47(10-84)$ & $4(-35-44)$ \\
\hline F statistic (df) & $9.2(26584)$ & $3.0(26185)$ & $2.8(26184)$ \\
\hline p-value & 0.001 & 0.105 & 0.139 \\
\hline \multicolumn{4}{|l|}{ Nonwhite fish ${ }^{\#}$} \\
\hline$\geqslant 1$ week & $91(61-121)$ & $50(20-81)$ & $29(-3-61)$ \\
\hline $1-3$ month & $71(39-103)$ & $42(10-75)$ & $27(-6-60)$ \\
\hline F statistic $(\mathrm{df})$ & $19.4(26584)$ & $5.9(26185)$ & 1.9 (26184) \\
\hline p-value & $* * *$ & 0.001 & 0.078 \\
\hline \multicolumn{4}{|l|}{ White fish ${ }^{\#}$} \\
\hline$\geqslant 1$ day & $90(56-124)$ & $53(19-88)$ & $27(-9-63)$ \\
\hline $1-3$ month & $93(55-131)$ & $65(26-103)$ & $49(10-88)$ \\
\hline F statistic (df) & $15.3(26584)$ & $6.1(26185)$ & $3.1(26184)$ \\
\hline $\mathrm{p}$-value & $* * *$ & 0.013 & 0.363 \\
\hline
\end{tabular}

Data are presented as $\mathrm{n}(95 \%$ confidence interval) unless otherwise stated. Model A adjusted for height, height ${ }^{2}$, age, age $^{2}$ and sex. Model B adjusted for height, height ${ }^{2}$, age, age, sex, smoking status, number of cigarettes smoked per day, social class and activity level. Model $\mathrm{C}$ adjusted for height, height ${ }^{2}$, age, age $^{2}$, sex, smoking status, number of cigarettes smoked per day, social class, activity level and other dietary intakes. df: degrees of freedom; \#. reference category less than once per month; ${ }^{\uparrow}$ : less than once per week. $\mathrm{n}=6186$. ${ }^{* * *} \mathrm{p}<0.001$. 
Table 4.-Prevalence of respiratory symptoms and odds ratios (OR) for association with fruit consumption

\begin{tabular}{|c|c|c|c|c|}
\hline & Prevalence & Model A & Model B & Model C \\
\hline \multicolumn{5}{|c|}{ Phlegm in the morning in winter } \\
\hline \multicolumn{5}{|c|}{ Frequency of fruit consumption } \\
\hline$\geqslant 1$ day & 11.0 & $0.29(0.23-0.36)$ & $0.64(0.49-0.83)$ & $0.66(0.51-0.87)$ \\
\hline $1-6$ week & 15.0 & $0.40(0.33-0.48)$ & $0.66(0.54-0.81)$ & $0.69(0.56-0.85)$ \\
\hline $1-3$ month & 23.1 & $0.66(0.54-0.82)$ & $0.78(0.63-0.98)$ & $0.82(0.65-1.02)$ \\
\hline$<1$ month & 31.2 & 1.0 & 1.0 & 1.0 \\
\hline Chi-squared (df) & & $163.3(3)$ & $25.8(3)$ & $18.9(3)$ \\
\hline p-value & & $* * *$ & 0.001 & 0.006 \\
\hline \multicolumn{5}{|c|}{ Phlegm for $\geqslant 3$ months $\cdot \mathrm{yr}^{-1}$} \\
\hline \multicolumn{5}{|c|}{ Frequency of fruit consumption } \\
\hline$\geqslant 1$ day & 6.4 & $0.27(0.20-0.36)$ & $0.67(0.49-0.91)$ & $0.66(0.48-0.92)$ \\
\hline $1-6$ week & 9.2 & $0.40(0.32-0.49)$ & $0.71(0.56-0.89)$ & $0.73(0.57-0.93)$ \\
\hline $1-3$ month & 16.0 & $0.72(0.57-0.91)$ & $0.90(0.70-1.15)$ & $0.93(0.72-1.21)$ \\
\hline$<1$ month & 21.2 & 1.0 & 1.0 & 1.0 \\
\hline Chi-squared (df) & & $135.3(3)$ & $19.7(3)$ & $15.8(3)$ \\
\hline p-value & & $* * *$ & $* * *$ & 0.002 \\
\hline \multicolumn{5}{|c|}{ Wheezing attacks with shortness of breath } \\
\hline \multicolumn{5}{|c|}{ Frequency of fruit consumption } \\
\hline$\geqslant 1$ day & 15.1 & $0.79(0.61-1.01)$ & $1.02(0.78-1.33)$ & $1.09(0.83-1.43)$ \\
\hline $1-6$ week & 13.1 & $0.66(0.53-0.82)$ & $0.82(0.65-1.02)$ & $0.87(0.68-1.10)$ \\
\hline $1-3$ month & 15.5 & $0.80(0.61-1.02)$ & $0.88(0.69-1.13)$ & $0.92(0.71-1.18)$ \\
\hline$<1$ month & 19.1 & 1.0 & 1.0 & 1.0 \\
\hline Chi-squared (df) & & $20.1(3)$ & $9.4(3)$ & $7.8(3)$ \\
\hline p-value & & 0.003 & 0.185 & 0.243 \\
\hline
\end{tabular}

Data are presented as OR (95\% confidence interval) unless otherwise stated. Model A adjusts for age and sex. Model B adjusts for age, sex, social class, smoking status and activity level. Model $\mathrm{C}$ adjusts for age, sex, social class, smoking status, activity level and all other dietary intakes. df: degrees of freedom; $n=7406 . * * *: p<0.001$.

and $\mathrm{E}$ and $\beta$-carotene were all correlated with one another $(0.21-0.75)$.

Fruit, vegetable and fish intake, pulmonary function and respiratory symptoms

There was a consistent dose/response relationship between more frequent fruit and green vegetable consumption and higher FEV1, after adjustment for age, height and sex (table 3; model A). These associations remained significant after further adjustment for confounders and intake of other foods (model C). There was a positive association between consumption of raw vegetables, cooked root vegetables, white and nonwhite fish intake and better pulmonary function (models A and B). After simultaneous adjustment for other dietary intakes these associations lost statistical significance.

Fruit consumption was associated with a reduced prevalence of phlegm. Odds ratios and 95\% confidence intervals (CI; adjusted for age, sex, social class, smoking, activity, vegetable and fish consumption) for the most frequent intake, more than once a day, compared with once a month or less were: phlegm in the morning in winter $0.66(0.51-0.87)$ and phlegm for 3 or more months per year $0.66(0.48-0.92)$. There was no association between fruit consumption and having shortness of breath (SOB) with wheezing in models B and C (table 4).

There were weaker and less consistent associations between consumption of vegetables and fish and respiratory symptoms. The most frequent consumption category for fish was at least once a week. When compared with eating fish less than once a month, white fish was associated with a reduced prevalence of SOB with wheezing $(0.83$ (0.67-1.01)) and phlegm in the morning in winter $(0.80(0.65-0.98))$. Eating nonwhite fish with the same frequency was weakly associated with a reduced risk of SOB with wheezing (0.89 (0.75-1.05)), after adjustment for confounding factors.
Plasma antioxidants and carotenoids, and pulmonary function and respiratory symptoms

Vitamin $\mathrm{C}$ and $\beta$-carotene levels were positively associated with pulmonary function, an SD score change in plasma levels corresponding to differences of $94 \mathrm{~mL}(62-126)$ in FEV1 for vitamin $\mathrm{C}$, and a $42 \mathrm{~mL}(10-74)$ difference for $\beta$-carotene, adjusted for the effects of age, sex and height. Table 5 shows that these differences remained significant for vitamin $\mathrm{C}$ in the fully adjusted model $\mathrm{C}$ but lost statistical significance for $\beta$-carotene after adjustment for social class, activity level and smoking. Vitamin A and E levels were not associated with pulmonary function.

Table 6 shows the associations of plasma vitamins and $\beta$-carotene on symptoms. Vitamins $C, E$ and $\beta$-carotene were

Table 5.-Difference in forced expiratory volume in one second $(\mathrm{mL})$ per SD score in plasma analytes

\begin{tabular}{lccr}
\hline Plasma analyte & Model A & Model B & \multicolumn{1}{c}{ Model C } \\
\hline Vitamin C & $94(62-126)$ & $50(14-85)$ & $49(13-85)$ \\
F statistic (df) & $189.7(5998)$ & $117.4(10935)$ & $90.3(13929)$ \\
Vitamin A & $22(-11-54)$ & $19(-14-51)$ & $22(-14-58)$ \\
F statistic (df) & $158.4(61024)$ & $93.5(10960)$ & $69.3(13929)$ \\
Vitamin E & $18(-13-49)$ & $-2(-34-30)$ & $-12(-47-24)$ \\
F statistic (df) & $185.0(61020)$ & $120.1(10956)$ & $90.27(13929)$ \\
$\beta$-carotene & $42(10-74)$ & $16(-17-49)$ & $11(-23-45)$ \\
F statistic (df) & $186.9(61024)$ & $120.4(10960)$ & $90.3(13929)$ \\
\hline
\end{tabular}

Data are presented as $\mathrm{n}(95 \%$ confidence interval) unless otherwise stated. Model A adjusted for height, height ${ }^{2}$, age, age $^{2}$ and sex. Model B adjusted for height, height ${ }^{2}$, sex, smoking status, number of cigarettes smoked per day, social class and activity level. Model $\mathrm{C}$ adjusted for height, height ${ }^{2}$, age, age ${ }^{2}$, sex, smoking status, number of cigarettes smoked per day, social class, activity level and other plasma analytes. df: degrees of freedom. 


\begin{tabular}{|c|c|c|c|}
\hline & Model A & Model B & Model C \\
\hline \multicolumn{4}{|c|}{ Phlegm in the morning in winter } \\
\hline Vitamin C & $0.74(0.62-0.88)$ & $1.01(0.83-1.23)$ & $1.02(0.84-1.25)$ \\
\hline Chi-squared (df) & $12.5(1)$ & 0.0 & $1.9(1)$ \\
\hline Vitamin A & $0.99(0.84-1.16)$ & $1.06(0.89-1.26)$ & $1.15(0.95-1.39)$ \\
\hline Chi-squared (df) & $0.1(1)$ & $0.4(1)$ & $1.9(1)$ \\
\hline Vitamin E & $0.76(0.64-0.91)$ & $0.87(0.72-1.04)$ & $0.80(0.65-0.99)$ \\
\hline Chi-squared (df) & $10.0(1)$ & $2.5(1)$ & $1.9(1)$ \\
\hline$\beta$-carotene & $0.76(0.63-0.93)$ & $0.88(0.71-1.10)$ & $0.92(0.74-1.15)$ \\
\hline Chi-squared (df) & $8.1(1)$ & $1.4(1)$ & $1.9(1)$ \\
\hline \multicolumn{4}{|c|}{ Phlegm $\geqslant 3$ months $\cdot \mathrm{yr}^{-1}$} \\
\hline Vitamin C & $0.70(0.56-0.86)$ & $0.92(0.73-1.17)$ & $0.94(0.74-1.20)$ \\
\hline Chi-squared (df) & $12.2(1)$ & $0.5(1)$ & $1.9(1)$ \\
\hline Vitamin A & $1.01(0.84-1.22)$ & $1.11(0.91-1.35)$ & $1.17(0.94-1.46)$ \\
\hline Chi-squared (df) & $0.0(1)$ & $0.9(1)$ & $1.9(1)$ \\
\hline Vitamin E & $0.80(0.65-0.98)$ & $0.93(0.76-1.14)$ & $0.87(0.68-1.11)$ \\
\hline Chi-squared (df) & $5.1(1)$ & $0.5(1)$ & $1.9(1)$ \\
\hline$\beta$-carotene & $0.68(0.52-0.87)$ & $0.78(0.59-1.03)$ & $0.81(0.61-1.09)$ \\
\hline Chi-squared (df) & $10.7(1)$ & $3.3(1)$ & $1.9(1)$ \\
\hline \multicolumn{4}{|c|}{ Wheezing attacks with shortness of breath } \\
\hline Vitamin C & $0.97(0.82-1.14)$ & $1.06(0.88-1.28)$ & $1.02(0.84-1.24)$ \\
\hline Chi-squared (df) & $0.1(1)$ & $0.3(1)$ & $7.9(1)$ \\
\hline Vitamin A & $1.20(1.02-1.40)$ & $1.27(1.07-1.50)$ & $1.31(1.09-1.58)$ \\
\hline Chi-squared (df) & $4.9(1)$ & $7.5(1)$ & $7.9(1)$ \\
\hline Vitamin E & $1.00(0.86-1.18)$ & $1.05(0.89-1.24)$ & $0.93(0.77-1.13)$ \\
\hline Chi-squared (df) & $0.0(1)$ & $0.4(1)$ & $7.9(1)$ \\
\hline$\beta$-carotene & $1.03(0.89-1.22)$ & $1.12(0.94-1.32)$ & $1.10(0.92-1.31)$ \\
\hline Chi-squared (df) & $0.2(1)$ & $0.2(1)$ & $7.9(1)$ \\
\hline
\end{tabular}

Data are presented as odds ratio (95\% confidence interval) unless otherwise stated. Model A adjusts for age and sex. Model B adjusts for age, sex, social class, smoking status and activity level. Model C adjusts for age, social class, smoking status, activity level and all other plasma analytes. df: degrees of freedom. $n=982$.

all associated with reduced risk of symptoms of phlegm production (model A). After full adjustment for confounders, this association remained for vitamin $\mathrm{E}$ and the risk of having phlegm in the morning in winter $(0.20(0.65-0.99))$. Plasma vitamin A was significantly associated with an increased risk of SOB with attacks of wheeze (1.31 (1.09-1.58)). Table 7 shows the effect of simultaneously estimating the relationship between fruit intake and plasma vitamin levels and lung function. The dose/response relationship between fruit consumption and pulmonary function remained $(p=0.05)$ a difference of $137 \mathrm{~mL}$ (1-272) in FEV1 for the most frequent intake category compared with rarely or never. After taking into account fruit consumption and other plasma vitamin levels, a significant relationship also remained between vitamin $\mathrm{C}$ and FEV1.

Eating fruit once or more per day, and an SD change in vitamin $\mathrm{E}$ were independently associated with a reduced risk of phlegm in the morning in winter $(0.47(0.24-0.93)$ and 0.76 (0.61-0.94), respectively). Only eating fruit once or more a day was independently associated with a reduction in phlegm for 3 months or more per year $(0.42(0.18-0.98))$.

\section{Discussion}

The findings of this study add to previous studies, since the authors were able to analyse data for two types of exposure: fruit, vegetable and fish intake and plasma vitamins and carotenoids, and outcome data for two aspects of respiratory health, pulmonary function and symptoms in the same individuals.

Fruit, vegetable and fish consumption, and plasma vitamin $\mathrm{C}$ were shown to be positively associated with pulmonary function, and fruit intake and plasma vitamin $\mathrm{E}$ were associated with reduced prevalence of phlegm production.

There was a dose/response relationship between consumption of fresh fruit and pulmonary function $(p<0.001)$. A $132 \mathrm{~mL}$ difference in FEV1 between those eating fresh fruit less than once a month and those eating fruit once or more a day is consistent with other large epidemiological studies [3-7]. Consumption of raw and cooked vegetables and fish were also associated with better pulmonary function, the estimated size of the effect being $30-50 \%$ that of fresh fruit. The findings for fish intake and pulmonary function are consistent with findings by SHARP et al. [10].

Fresh fruit intake was associated with a $30-40 \%$ reduction in the prevalence of phlegm in the morning in winter and phlegm for 3 months or more per year. This is consistent with the findings from a study of the onset of chronic nonspecific lung disease [21]. No link with fruit intake and SOB was found with wheezing. This contrasts with analysis of the 1958 birth cohort data, when subjects were aged 33 yrs, which showed reduced risk of wheezing symptoms [8]. FORASTIERE et al. [9] showed a protective role for fruit consumption against wheezing illness in children, though this was not demonstrated in the Ten Towns study of children [6].

A difference of $49 \mathrm{~mL}$ in FEV1 was associated with an SD change in plasma vitamin $\mathrm{C}$. Positive associations between plasma vitamin $\mathrm{C}$ and pulmonary function have been reported elsewhere $[12,13]$.

Plasma vitamin E was associated with a reduced prevalence of phlegm production. Previously, dietary vitamin E has been reported to be positively associated with respiratory health and allergic sensitisation in adults [4, 13, 22-26], and two population-based studies of children have suggested a beneficial role for vitamin $\mathrm{E}$ on respiratory health [27, 28].

The same broad consistency was not observed in the effect 
Table 7. - Simultaneous adjustment for fruit intake and plasma analyte levels on respiratory symptoms and difference in forced expiratory volume in one second $\left(F E V_{1}\right)$.

\begin{tabular}{|c|c|c|c|}
\hline & Model A & Model B & Model C \\
\hline \multicolumn{4}{|c|}{ Phlegm $\geqslant 3$ months $\cdot \mathrm{yr}^{-1}$} \\
\hline \multicolumn{4}{|c|}{ Fruit intake } \\
\hline$\geqslant 1$ day & $0.40(0.17-0.92)$ & & $0.42(0.18-0.98)$ \\
\hline $1-6$ week & $0.82(0.46-1.44)$ & & $0.85(0.47-1.51)$ \\
\hline 1-3 month & $0.86(0.46-1.63)$ & & $0.86(0.45-1.64)$ \\
\hline Vitamin $\mathrm{C}$ & & $0.97(0.77-1.24)$ & $1.02(0.80-1.31)$ \\
\hline Vitamin A & & $1.15(0.92-1.44)$ & $1.16(0.93-1.09)$ \\
\hline Vitamin E & & $0.88(0.69-1.11)$ & $0.88(0.69-1.11)$ \\
\hline$\beta$-carotene & & $0.80(0.60-1.07)$ & $0.81(0.60-1.09)$ \\
\hline Chi-squared (df) & $81.7(10)$ & $81.1(11)$ & $86.2(14)$ \\
\hline \multicolumn{4}{|c|}{ Phlegm in the morning in winter } \\
\hline \multicolumn{4}{|c|}{ Fruit intake } \\
\hline$\geqslant 1$ day & $0.48(0.25-0.92)$ & & $0.47(0.24-0.93)$ \\
\hline $1-6$ week & $0.67(0.40-1.10)$ & & $0.66(0.40-1.10)$ \\
\hline 1-3 month & $0.67(0.38-1.18)$ & & $0.65(0.36-1.15)$ \\
\hline Vitamin C & & $1.02(0.84-1.25)$ & $1.07(0.87-1.30)$ \\
\hline Vitamin A & & $1.15(0.95-1.39)$ & $1.15(0.95-1.40)$ \\
\hline Vitamin E & & $0.76(0.62-0.95)$ & $0.76(0.61-0.94)$ \\
\hline$\beta$-carotene & & $0.93(0.75-1.15)$ & $0.94(0.76-1.18)$ \\
\hline Chi-squared (df) & $96.1(10)$ & $99.0(11)$ & $104.0(14)$ \\
\hline \multicolumn{4}{|l|}{$\mathrm{FEV}_{1}^{\#}$} \\
\hline \multicolumn{4}{|l|}{ Fruit intake } \\
\hline$\geqslant 1$ day & $182(49-315)$ & & $137(1-272)$ \\
\hline $1-6$ week & $133(20-246)$ & & $116(3-229)$ \\
\hline 1-3 month & $70(-58-198)$ & & $67(-61-194)$ \\
\hline Vitamin C & & $64(26-101)$ & $57(18-95)$ \\
\hline Vitamin A & & $24(-13-61)$ & $24(-14-61)$ \\
\hline Vitamin E & & $-9(-46-28)$ & $-9(-45-28)$ \\
\hline$\beta$-carotene & & $12(-23-47)$ & $9(-26-44)$ \\
\hline F statistic (df) & 86.4 (13924) & $81.0(14923)$ & $67.2(17920)$ \\
\hline Mean squares & 3567286 & 2580762 & 2134713 \\
\hline
\end{tabular}

Data are presented as odds ratio (95\% confidence interval) for adjustment for fruit intake and plasma analyte levels on respiratory symptoms ( $\mathrm{n}=98)$, and as $\mathrm{n}(95 \%$ confidence interval) for difference in FEV1 $(\mathrm{mL} ; \mathrm{n}=937)$ unless otherwise stated. Models A, B and C adjusted for age, sex, smoking, social class and activity level. df: degrees of freedom. \# : models adjusted for age, age ${ }^{2}$, height and height $^{2}$, sex, smoking, number of cigarettes smoked per day, social class and activity level.

of plasma analytes on respiratory health as was, for example, fruit intake. There are difficulties in comparing data and interpreting analyses when the nature of the explanatory factors differ. When fruit consumption and plasma analytes were included in the same statistical models, fruit intake remained significantly associated with lung function and the prevalence of phlegm. Vitamin $\mathrm{C}$ was important in predicting lung function and vitamin $\mathrm{E}$ was associated with a reduced prevalence of phlegm in the morning during winter.

\section{Causal inferences}

Findings from this and many other studies support the original hypothesis proposed by SEATON et al. [29] that dietary factors, particularly antioxidant rich foods, influence respiratory health. Data from the current study show a dose/ response relationship between dietary intakes of fruit and vegetables, and pulmonary function and respiratory symptoms. The current study reports differences in relationships between dietary intakes and plasma analytes on the prevalence of symptoms of phlegm production and SOB with attacks of wheezing. These observations may reflect different effects of diet on different aspects of airway disease.

A recent prospective study presented evidence of the reversible effects of fruit consumption on pulmonary function [7], though this was in contrast to the findings of the Caerphilly Heart study [4]. Experimental data from laboratory protocols that administered large doses of vitamin $\mathrm{C}$ to healthy and asthmatic subjects who subsequently underwent airway hyperactivity challenges, show evidence of a protective effect of vitamin $C[30,31]$. In contrast, vitamin $C$ supplementation trials in small numbers of asthmatic subjects have failed to show beneficial effects [32, 33]. However, studies of combined vitamin $\mathrm{C}, \mathrm{E}$ and $\beta$-carotene supplementation in subjects exposed to ozone have shown benefits for pulmonary function $[34,35]$. A large vitamin $\mathrm{E}$ and $\beta$-carotene supplementation trial showed no beneficial effect on symptoms associated with chronic obstructive pulmonary disease [36].

Inconsistencies that have arisen from previous observational studies are probably due to variations in measuring exposures, and to some extent outcomes, particularly with respiratory symptoms or disease definitions. The bulk of these studies are in adults and thus any inconsistencies in findings from children may be due to general physiological differences, and perhaps such study findings should not be extrapolated to adult populations.

\section{Limitations, measurement and bias}

As cross-sectional data were analysed, findings in this study should be interpreted with caution as they lack temporality. Findings from this study are consistent with many previous epidemiological reports, which are based, in the main, on cross-sectional observations. 
There have been reports to support the hypothesised protective role of other dietary factors, such as flavenoids and magnesium [4, 28, 37]. However, the authors were not able to test these associations in the data as hard fruits, which are a major source of flavenoids, could not be distinguished from other fruits, and data on individual micronutrient intakes were not available.

Dietary intakes assessed by food frequency are a crude measure of consumption. However, estimates of the effects on pulmonary function and symptom prevalence were highly statistically significant. A more refined measure of dietary consumption may have resulted in larger effect sizes. It is not clear how plasma antioxidant levels relate to overall antioxidant status in the body. However, plasma vitamins $\mathrm{C}$, $\mathrm{A}, \mathrm{E}$ and $\beta$-carotene are valid biochemical indicators of nutrient status [38].

Reporting bias is unlikely as participants were asked questions about many aspects of health, not solely respiratory, and about many lifestyle indicators including diet, and so it is unlikely that subjects would have been aware of individual hypotheses.

\section{Conclusions}

The potential public health significance of these findings, if there are causal links, are important as clinically significant benefits in terms of both pulmonary function and the reduced prevalence of symptoms are apparent from the authors' and other epidemiological studies. The consistent effect of fresh fruit compared with those of plasma micronutrients that has been shown in this study suggests that the active agent(s), or the most beneficial combinations of dietary components are contained within whole foods. It may be that improving the diet, by increasing the consumption of fresh fruit, vegetables and fish, rather than consumption of vitamin supplements, will be beneficial in helping to protect against airway disease.

\section{Appendix 1: Dietary intake questions}

"How often do you eat fresh fruit?"

"How often do you eat cooked green vegetables such as peas, broccoli, cabbage, spinach, cauliflower, green beans, and so on?"

"How often do you eat cooked root vegetables such as carrots, parsnips, turnips, and so on?"

"How often do you eat raw vegetables or salad?"

"How often do you eat white fish, such as cod, haddock, whiting, sole or plaice?"

"How often do you eat other types of fish, such as herring, tuna, mackerel, salmon or kippers?"

Possible answers:

$\geqslant 6$ times a day

4-5 times a day

2-3 times a day

Once a day

5-6 times a week

2-4 times a week

Once a week

1-3 times a month

Less often or never

\section{Appendix 2: Respiratory symptom questions}

"Do you usually bring up any phlegm from your chest, first thing in the morning in winter?"

"Do you bring up phlegm like this on most days for as much as 3 months each year?"

"Have you ever had attacks of shortness of breath with wheezing?"

\section{References}

1. Heffner J, Repine J. Pulmonary strategies of defence: state of the art. Am Rev Respir Dis 1989; 140: 531-534.

2. Lee TH, Arn JP. Prospects for modifying the allergic response by fish oil diet. Clin Allergy 1986; 16: 89-100.

3. Strachan D, Cox B, Erzinclioglu S, Walters D, Whichelow M. Ventilatory function and winter fresh fruit consumption in a random sample of British adults. Thorax 1991; 46: 624-629.

4. Butland B, Fehily A, Elwood P. Diet, lung function, and lung function decline in a cohort of 2512 middle aged men. Thorax 2000; 55: 102-108.

5. Tabak C, Smit H, Rasanen L, et al. Dietary factors and pulmonary function: a cross sectional study in middle aged men from three European countries. Thorax 1999; 54: 1021-1026.

6. Cook D, Carey I, Whincup P, et al. Effect of fresh fruit consumption on lung function and wheeze in children. Thorax 1997; 52: 628-633.

7. Carey I, Strachan D, Cook D. Effects of changes in fresh fruit consumption on ventilatory function in healthy British adults. Am J Respir Crit Care Med 1998; 158: 728-733.

8. Butland B, Strachan D, Anderson H. Fresh fruit intake and asthma symptoms in young British adults: confounding or effect modification by smoking. Eur Respir J 1999; 13: 744-750.

9. Forastiere F, Pistelli R, Sestini P, et al. Consumption of fresh fruit rich in vitamin $\mathrm{C}$ and wheezing symptoms in children. Thorax 2000; 55: 283-288.

10. Sharp D, Rodriguez B, Shahar E, Hwang L, Burchfiel C. Fish consumption may limit the damage of smoking on the lung. Am J Respir Crit Care Med 1994; 150: 983-987.

11. Schwartz J, Weiss S. Dietary factors and their relation to respiratory symptoms. The Second National Health and Nutrition Examination Survey. Am J Epidemiol 1990; 132: 67-76.

12. Ness A, Khaw K, Bingham S, Day N. Vitamin C status and respiratory function. Eur J Clin Nutr 1996; 50: 573-579.

13. $\mathrm{Hu} \mathrm{G}$, Cassano P. Antioxidant nutrients and pulmonary function: the Third Health and Nutrition Examination Survey (NHANES III). Am J Epidemiol 2000; 151: 975-981.

14. Morabia A, Menkes M, Comstock G, Tockman M. Serum retinol and airway obstruction. Am J Epidemiol 1990; 132: 77-82.

15. Chuwers $\mathrm{P}$, Barnhart $\mathrm{S}$, Blanc $\mathrm{P}$, et al. The protective effect of beta-carotene and retinol on ventilatory function in an asbestos-exposed cohort. Am J Respir Crit Care Med 1997; 155: 1066-1071.

16. Finch S, Doyle W, Lowe C, Bates C, Prentice A, Smithers G. National Diet and Nutrition Survey. London, UK, The Stationary Office, 1998.

17. Scottish Health Survey. Scottish Health Survey 1995. Volume 1. Erens B, Dong W, eds. Edinburgh, The Stationery Office, 1997.

18. Office of Population Censuses and Surveys. Classification of Occupations. London, HMSO, 1980.

19. Heilinger F. Modification of methods described fall too. Curr Sep 1980; 2: 342-356.

20. Thurnham D, Smith E, Flora P. Concurrent liquidchromatographic assay of retinol, alpha-tocopherol, lycopene, and beta-cryptoxanthin in plasma, with tocopherol acetate as an internal standard. Clin Chem 1988; 34: 377-381. 
21. Miedema I, Feskens E, Heederik D, Kromhout D. Dietary determinants of the long-term incidence of chronic nonspecific lung disease. Am J Epidemiol 1993; 138: 37-45.

22. Grievnk L, Smit H, Ocke M, van't Veer P, Kromhout D. Dietary intake of antioxidant (pro)-vitamins, respiratory symptoms and pulmonary function: the MORGEN study. Thorax 1998; 53: 166-171.

23. Dow L, Tracey M, Villar A, et al. Does dietary intake of vitamins $\mathrm{C}$ and $\mathrm{E}$ influence lung function in older people. $\mathrm{Am}$ J Respir Crit Care Med 1996; 154: 1401-1404.

24. Britton J, Pavord I, Richards K, et al. Dietary antioxidant vitamin intake and lung function in the general population. Am J Respir Crit Care Med 1995; 151: 1383-1387.

25. Troisi R, Willett W, Weiss S, Trichopoulos D, Rosner B, Speizer F. A prospective study of diet and adult-onset asthma. Am J Respir Crit Care Med 1995; 151: 1401-1408.

26. Fogerty A, Lewis S, Weiss S, et al. Dietary vitamin E, IgE concentrations, and atopy. Lancet 2000; 356: 1573-1574.

27. Kelly YJ. Risk factors for respiratory morbidity in Merseyside schoolchildren. University of Liverpool, UK, 1997 (PhD Thesis).

28. Hijazi N, Abalkhail B, Seaton A. Diet and childhood asthma in a society in transition: a study in urban and rural Saudi Arabia. Thorax 2000; 55: 775-779.

29. Seaton A, Godden D, Brown K. Increase in asthma: a more toxic environment or a more susceptible population? Thorax 1994; 49: 171-174.

30. Mohsenin V. Effect of vitamin $\mathrm{C}$ on $\mathrm{NO}_{2}$-induced airway hyperresponsiveness in normal subjects. Am Rev Respir Dis 1987; 136: 1408-1411.
31. Zuskin E, Lewis A, Bouhuys A. Inhibition of histamine induced airway constriction by ascorbic acid. J Allergy Clin Immunol 1973; 51: 218-226.

32. Malo JL, Cartier A, Pineau L, et al. Lack of acute effects of ascorbic acid on spirometry and airway responsiveness to histamine in subjects with asthma. J Allergy Clin Immunol 1986; 78: 1153-1158.

33. Ting S, Mansfield L, Yarborough J. The effects of ascorbic acid on pulmonary functions in mild asthma. J Asthma 1983; 20: 39-42.

34. Romieu I, Meneses F, Ramirez M, et al. Antioxidant supplementation and respiratory functions among workers exposed to high levels of ozone. Am J Respir Crit Care Med 1998; 158: 226-232.

35. Grievnk L, Jansen S, van't Veer P, et al. Acute effects of ozone on pulmonary function of cyclists receiving antioxidant supplements. Occup Environ Med 1998; 55: 13-17.

36. Rautalahti M, Virtamo J, Haukka J, et al. The effect of alpha-tocopherol and beta-carotene supplementation on COPD symptoms. Am J Respir Crit Care Med 1997; 156: 1447-1452.

37. Britton J, Pavord I, Richards K, et al. Dietary magnesium, lung function, wheezing, and airway hyper-reactivity in a random adult population sample. Lancet 1994; 344: 357-362.

38. Bates CJ, Thurnham DL, Bingham SA, Margetts BM, Nelson M. Biochemical markers of nutrient intake. In: Margetts BM, Nelson M, eds. Design Concepts in Nutritional Epidemiology. 2nd edn. Oxford, Oxford University Press, 1997; pp. 170-240. 